\title{
(2) OPEN ACCESS \\ Long-term progression-free survival of patients with metastatic melanoma or renal cell carcinoma following high-dose interleukin-2
}

\author{
Joseph I Clark, ${ }^{1}$ Brendan Curti, ${ }^{2}$ Elizabeth J Davis, ${ }^{3}$ Howard Kaufman, ${ }^{4}$ \\ Asim Amin, ${ }^{5}$ Ajjai Alva, ${ }^{6}$ Theodore F Logan, ${ }^{7}$ Ralph Hauke, ${ }^{8}$ Gerald P Miletello, ${ }^{9}$ \\ Ulka Vaishampayan, ${ }^{10}$ Douglas B Johnson, ${ }^{3}$ Richard L White, ${ }^{5}$ \\ Peter H Wiernik (D) , 11 Janice P Dutcher (D) ${ }^{11}$
}

Additional material is published online only. To view, please visit the journal online (http://dx.doi.org/10. 1136/jim-2020-001650).

For numbered affiliations see end of article.

\section{Correspondence to} Dr Janice P Dutcher, Medicine, New York Medical College, Valhalla, NY 10463, USA; jpd4401@aol.com

Presented in part at the Society for Immunotherapy of Cancer Annual Meeting, 2017.

Accepted 19 January 2021 Published Online First 4 February 2021

\section{ABSTRACT}

High-dose interleukin-2 (HD IL-2) was approved in the 1990s after demonstrating durable complete responses (CRs) in some patients with metastatic melanoma (mM) and metastatic renal cell carcinoma (mRCC). Patients who achieve this level of disease control have also demonstrated improved survival compared with patients who progress, but limited data are available describing the long-term course. The aim of this study was to better characterize long-term survival following successful HD IL-2 treatment in patients with no subsequent systemic therapy. Eleven HD IL-2 treatment centers identified patients with survival $\geq 5$ years after HD IL-2, with no subsequent systemic therapy. Survival was evaluated from the date of IL-2 treatment to June 2017. Treatment courses consisted of 21 -week cycles of HD IL-2. Patients were treated with HD IL-2 alone, or HD IL-2 followed by local therapy to achieve maximal response. 100 patients are reported: 54 patients with $\mathrm{mM}$ and 46 patients with $\mathrm{mRCC}$. Progression-free survival (PFS) after HD IL-2 ranges from $5+$ years to $30+$ years, with a median follow-up of $10+$ years. $27 \mathrm{mRCC}$ and $32 \mathrm{mM}$ are alive $\geq 10$ years after IL-2. Thus, a small subset of patients with $\mathrm{mM}$ and $\mathrm{mRCC}$ achieve long-term PFS ( $\geq 5$ years) after treatment with HD IL-2 as their only systemic therapy. The ability of HD IL-2 therapy to induce prolonged PFS should be a major consideration in studies of new immunotherapy combinations for $\mathrm{mM}$ and $\mathrm{mRCC}$.

\section{INTRODUCTION}

In the last decade, immunotherapy has re-emerged as meaningful treatment for advanced cancer, yielding responses in a broader spectrum of malignancies, although a small percentage of responses. This is leading to continued investigation of immunotherapy in advanced cancer, with treatment goals of durable response and prolonged clinical benefit.

High-dose interleukin (IL)-2 therapy, a cytokine immunotherapy long in use, is associated with durable treatment-free responses, prolonged clinical benefit from response and long-term survivors in a proportion of responding patients with metastatic melanoma $(\mathrm{mM})$ and metastatic renal cell carcinoma (mRCC), as reported in early trials. ${ }^{1-3}$ Contemporary multi-institutional reports continue to demonstrate durable response and survival (table 1). ${ }^{4-10}$ In some reports, median overall survival (OS) was not reached for patients achieving complete response (CR) or partial response (PR), after nearly 4 years of follow-up. ${ }^{67}$ Median OS for patients with stable disease was also quite durable. ${ }^{467}$

HD IL-2 has been used clinically for $>30$ years, yielding extensive clinical experience, and recommendations for management guidelines and safety protocols. ${ }^{911}$ Although currently requiring inpatient monitoring, HD IL-2 treatment centers have developed well-designed screening and treatment protocols which guide the safe management of patients undergoing this treatment (online supplemental table S1). This is similar to the evolution of treatment centers for marrow/stem cell transplantation and now chimeric antigen receptor $T$ cell therapy.

Additionally, as immune check point inhibitors (CPI) have produced benefit for patients with $\mathrm{mM}$ and $\mathrm{mRCC}$, CPIs are now being evaluated in combination with other diseasespecific therapies for these diseases. ${ }^{12-15}$ Thus, studies combining CPIs with HD IL-2 are ongoing (online supplemental table S2) with the goal of increasing response rates and possibly increasing duration of response and survival.

To encourage these efforts, we present data describing $\geq 5$-year survival following HD IL-2 treatment with no subsequent systemic therapy, to better demonstrate the course for these patients over years.

\section{METHODS}

Eleven HD IL-2 treatment centers contributed their patient experience by querying their Investigational Review Board-approved databases and specifically identifying patients remaining alive 5 years or more after IL-2 treatment with this as their only systemic therapy. Patient 
Table 1 Contemporary multi-institutional reports-HD IL-2 outcome

\begin{tabular}{|c|c|c|}
\hline Report & Response & Survival \\
\hline $\begin{array}{l}\text { Clark et } \text { al }^{4} \\
\text { RCC (2011-2015), sequenced with targeted therapy } \\
\text { N=352 (328 with response data) } \\
\text { PROCLAIM registry database }\end{array}$ & $\begin{array}{l}\text { CR 4\%, PR 13\%, SD 39\%, PD 43\% } \\
\text { CR+PR+SD 53\% }\end{array}$ & $\begin{array}{l}\text { Median OS-NR for CR, PR, SD } \\
\text { Median OS—PD-15.5 months } \\
\text { PD followed by TT-med OS } 29.7 \text { months; PD no } \\
\text { TT—med OS } 8.5 \text { months } \\
\text { 2.5-year OS—CR } 100 \% \text {; PR } 75 \% \text {, SD 78\%, PD 39\% }\end{array}$ \\
\hline $\begin{array}{l}\text { McDermott et }\left.a\right|^{5} \\
\text { RCC } n=120 \\
\text { Multi-institution, prospective trial }\end{array}$ & $\begin{array}{l}\text { ORR } 25 \%, \text { CR 3, PR } 27 \\
13(11 \%) \text { progression-free at } 3 \text { years }\end{array}$ & $\begin{array}{l}\text { Median OS } 42.8 \text { months } \\
80 \% \text { TT after IL-2 }\end{array}$ \\
\hline $\begin{array}{l}\text { Alva et a }{ }^{6} \\
\text { mM }(2005-2012)-n=170 \\
\text { RCC }(2005-2012)-n=192 \\
\text { Survival current } 2015 \\
\text { PROCLAIM registry database }\end{array}$ & $\begin{array}{l}\mathrm{mM}: \text { CR } 5 \% \text { PR } 10 \% \text { SD } 22 \% \\
\text { CR+PR+SD } 58 \% \text { median f/u } 43.1 \text { months } \\
\text { RCC: CR 6\%, PR 9\%, SD 22\% } \\
\text { CR+PR+SD 70\% median f/u } 46.6 \text { months }\end{array}$ & $\begin{array}{l}\text { Median OS } 19.6 \text { months } \\
\text { Median OS-NR for CR, PR } \\
\text { Median OS } 33.4 \text { months-SD } \\
\text { Median OS } 41 \text { months } \\
\text { Median OS-NR for CR, PR } \\
\text { Median OS } 49.6 \text { months-SD }\end{array}$ \\
\hline $\begin{array}{l}\text { Stenehjem et al } \\
\text { RCC } n=391 \\
\text { U Utah 1988-2013 } \\
\text { U Mich 1997-2013 }\end{array}$ & $\begin{array}{l}\text { CR } 9 \% \text { PR } 10 \% \text {, SD } 32 \% \text { PD } 42 \% \\
\text { CR+PR+SD } 51 \%\end{array}$ & $\begin{array}{l}\text { Median OS CR-13+ years } \\
\text { Median OS PR-37.8 months } \\
\text { Median OS SD-34.4 months }\end{array}$ \\
\hline
\end{tabular}

$\mathrm{CR}$, complete response; f/u, follow-up; IL, interleukin; mM, metastatic melanoma; N, number; NR, not reached; ORR, overall response rate; OS, overall survival; PD, progressive disease; PR, partial response; RCC, renal cell carcinoma; SD, stable disease; TT, targeted therapy; U, university.

consent for IL-2 follow-up had been previously obtained. Records were queried for age/date of diagnosis, date/sites of metastatic disease, date(s) of HD IL-2 treatment, doses/ courses received, best response by investigator assessment, subsequent course of disease, subsequent interventions, long-term toxicity and current functional and disease status. All IL-2-treated patients meeting enrollment criteria were evaluated. Data collection commenced from 2016 to 2017. Progression-free survival (PFS) was calculated from the time of IL-2 treatment until recurrence or June 2017. Survival was defined from the time of HD IL-2 treatment until June 2017. Data on PFS/treatment-free survival are presented.

\section{High-dose IL-2 treatment}

These centers used the original treatment schedule of 5 days of treatment (one cycle), followed by a 9-day break, then followed by a second 5-day cycle (total 2 -week treatment equals one course). Doses of IL-2 at either 600,000 U/ $\mathrm{kg} / \mathrm{dose}$, the original Cytokine Working Group dose, or $720,000 \mathrm{U} / \mathrm{kg} /$ dose, the original National Cancer Institute (NCI) dose, were used. Intravenous bolus dosing was initiated on an every 8 -hour schedule, but time between doses was extended to allow toxicity to recover, as per institutional protocols. All patients received HD IL-2 alone as systemic treatment (see online supplemental table S1 for guide to screening and management).

Localized surgery or radiation therapy (usually stereotactic radiosurgery (SRS)) could be administered to patients achieving PR to maximize response, according to the center's practice and such patients were considered 'surgical/ SRS complete responders', if no additional systemic therapy was added.

\section{RESULTS}

From the 11 participating centers, 100 patients were identified who achieved CR, surgical/SRS CR or PR following HD IL-2, with no subsequent systemic therapy and with survival data available at $\geq 5$ years from IL-2 treatment. All subjects were alive at the time of data collection in 2017.
There was no attempt to derive a percentage of all treated, as the goal was to evaluate the status of their survival. Of the patients identified, 54 had $\mathrm{mM}$ and 46 had mRCC. The ratio of male/female patients who achieved response are consistent with the literature of patients diagnosed with mRCC and mM (online supplemental table S3). Sites of metastatic disease are listed in online supplemental table S3, with lung and lymph node involvement in $25 \%$ and $40 \%$ of patients with $\mathrm{mM}$, respectively, and in $50 \%$ and $20 \%$ of patients with mRCC, respectively. Other sites of disease included bone, liver, gastrointestinal tract and brain. In terms of treatment received, the majority (66\%) received two to three courses of HD IL-2 (online supplemental table S4).

Among these 100 patients, $96 \%$ of patients with $\mathrm{mM}$ and 93\% of patients with mRCC achieved CR (table 2).

Of these, nine patients with $\mathrm{mM}$ and five patients with mRCC achieved durable CR with additional local therapy to limited residual disease following HD IL-2 treatment and never recurred. Two patients with $\mathrm{mM}$ and three patients with $\mathrm{mRCC}$ were considered PR with radiological residual, but had no subsequent progression or systemic therapy at $\geq 5$ years after HD IL- 2 .

For patients with $\mathrm{mM}$, median follow-up was $10+$ years, range $5+$ to $15+$ years, and for mRCC, median follow-up was $10.5+$ years, range $5+$ to $30+$ years (table $2 \mathrm{~A}$ ). In this sample, there was no correlation of long-term survival with sites of disease, gender or age at treatment.

The development of and/or persistence of grade 1-2 chronic toxicity occurred in $17 \%$ of patients (table 2B).

The most frequent chronic toxicities were grade 2 hypothyroidism requiring replacement therapy (five patients) and grade 1-2 arthralgia/arthritis (six patients). Grade 2 neuropathy occurred in one patient. Three patients developed grade 1-2 vitiligo. Grade 1 premature ventricular contractions and grade 1 normal pressure hydrocephalus developed in one patient each. No chronic disability related to treatment with HD IL-2 was identified or reported. 
Table 2 Patient outcomes and long-term toxicity $(A)$ response and survival, (B) long-term toxicity

\begin{tabular}{|c|c|c|}
\hline & $\begin{array}{l}\text { Metastatic } \\
\text { melanoma }\end{array}$ & $\begin{array}{l}\text { Metastatic renal } \\
\text { cell }\end{array}$ \\
\hline (A) Best response & $(n=54)$ & $(n=46)$ \\
\hline$C R$ & 43 & 38 \\
\hline Surgical/SRS CRs & 9 & 5 \\
\hline $\begin{array}{l}P R \\
\text { No further treatment }\end{array}$ & 2 & 3 \\
\hline Median follow-up & $10+$ years & $10.5+$ years \\
\hline Range follow-up & $5+$ to $15+$ years & $5+$ to $30+$ years \\
\hline $\begin{array}{l}\text { Alive }>10 \text { years after IL-2 with no } \\
\text { subsequent therapy }\end{array}$ & 32 patients & 27 patients \\
\hline
\end{tabular}

\begin{tabular}{ll}
\hline (B) Event & \# Patients \\
\hline Hypothyroidism—requiring replacement medication (grade 2) & 5 \\
\hline Arthralgias/Arthritis (grade 1-2) & 6 \\
\hline Vitiligo (grade 1-2) & 3 \\
\hline Neuropathy (grade 2) & 1 \\
\hline Premature ventricular contractions (grade 1) & 1 \\
\hline Normal pressure hydrocephalus (grade 1) & 1 \\
\hline
\end{tabular}

$\mathrm{CR}$, complete response; DFS, disease-free survival; IL-2, interleukin-2; PR, partial response; SRS, stereotactic radiosurgery.

\section{DISCUSSION}

The ability of treatment with HD IL-2 to produce durable treatment-free responses and survival in patients with advanced melanoma and RCC is an important starting point for ongoing immunotherapy clinical research. Early reports of $\mathrm{HD}$ IL-2 treatment demonstrated durable responses $(\mathrm{CR}+\mathrm{PR})$ lasting $>4+$ years and as long as $10+$ years. ${ }^{316}$ Klapper et al reported that inital response to HD IL-2 in patients with mRCC was the most predictive factor for long-term survival. ${ }^{16}$ Contemporary reports from single HD IL-2 centers confirm prolonged survival $(>3+$ to $5+$ years) among responders, with diagnoses of both $\mathrm{mM}$ and mRCC. ${ }^{17-19}$

Durable survival has also been noted among patients with $\mathrm{SD}$ in addition to patients with CR and PR in several reports, yielding clinical benefit $(\mathrm{CR}+\mathrm{PR}+\mathrm{SD})$ in $>50 \%$ of IL-2treated patients (table 1). ${ }^{467}$ Whereas patients achieving CR and many with PR experience prolonged treatment-free survival benefit, the achievement of durable SD may also provide a treatment-free interval and allow the opportunity for effective sequential therapy.

The current report was specifically designed to collate and emphasize some of the longest PFS and OS (decades) among patients treated with HD IL-2 at 11 HD IL-2 centers. ${ }^{8}$ Not surprisingly, these are primarily patients who achieved CR. It is of interest that long-term survival with HD IL-2 was not associated with gender, age or sites of metastatic disease. In the population reviewed, two-thirds (66/100) of patients received two to three of the 2 -week courses of HD IL-2 therapy, separated by several weeks or months. Only $20 \%$ of patients received one or fewer courses of treatment, while $26 \%$ received three or more courses of HD IL-2 therapy (online supplemental table S4). These data support a period of continued intermittent treatment in the absence of overt disease progression or toxicity. This report also demonstrates the limited and manageable residual toxicity from these short courses of intermittent treatment.

The most common chronic toxicities observed were grade 1-2 hypothyroidism and arthralgias which occurred in 11\% of patients in aggregate. These appeared to be tolerable with outpatient medical management and did not appear to impact subsequent function according to the investigators. Patients receiving HD IL-2 should be monitored for thyroid dysfunction and arthritis. This safety profile also suggests that combination studies including HD IL-2 may anticipate limited long-term toxicity from the IL-2 component of potential regimens.

While this report documents the long-term natural history for patients surviving $\geq 5$ years after HD IL-2 with no subsequent systemic therapy, the study has several limitations. First, the report focuses on patients who were managed at major tertiary referral centers experienced with HD IL-2 administration. This may have resulted in a selection bias. Second, although 100 patients were identified, this still represents a small sample size where broad conclusions may be inappropriate. Third, the study did not include information about prior adjuvant therapy or how patients were monitored for disease recurrence which may have differed across centers and could have influenced outcome. Despite these limitations, the study does provide insights into the natural history of an important population and helps define long-term outcomes for patients achieving prolonged survival after treatment with HD IL-2 and requiring no subsequent systemic therapy.

A major goal of this report is to provide an impetus for further evaluation of the combination of HD IL-2 with other therapies for $\mathrm{mM}$ and $\mathrm{mRCC}$, in particular immunotherapies, in an attempt to enhance the response rate and build on the durable clinical benefit, with the goal of increasing the percentage of long-term and treatment-free survivors.

One early study, suggesting this is possible, is that of Prieto et al who reported long-term follow-up of 36 patients with $\mathrm{mM}$ treated in an NCI study of the combination of the CPI, ipilimumab, plus HD IL-2 versus two other arms consisting of ipilimumab plus gp100 peptides (56 and 85 patients, respectively). ${ }^{20}$ Although the initial report presented a standard ipilimumab or IL-2 response rate, ${ }^{21}$ on longer follow-up (median of $84+$ months), the update reported that the CR rate climbed to $17 \%$ in the HD IL-2 plus ipilimumab arm compared with $6 \%$ and $7 \%$ in the two gp100 peptide combination arms. ${ }^{20}$ The 5 -year OS was updated to $25 \%$ with all but $1 \mathrm{CR}$ ongoing at $54+$ to $99+$ months. ${ }^{20}$ Surprisingly, the toxicity of the combination of HD IL-2 with ipilimumab was considerably less than prior reports of ipilimumab alone (grade 3-4 immune-related adverse events in this arm-17\%). ${ }^{20}$

The activity and relatively more limited toxicity profile of antiprogramed death-1 (anti-PD-1) antibodies compared with ipilimumab in the management of $\mathrm{mM}$ and $\mathrm{mRCC}$ has sparked interest in the development of combination immunotherapies, with initial reports being ipilimumab plus anti-PD-1 agents. ${ }^{12-15}$ Buchbinder et al have recently demonstrated the safe sequential use of HD IL-2 following PD-1 or programmed death-ligand 1 inhibition. ${ }^{22}$ The Prieto report suggests that combinations of CPIs with IL-2 are feasible, and thus the combination of HD IL-2 with 
anti-PD-1 agents should be evaluated to potentially enhance response rate and durable response, possibly leading to a greater proportion of long-term survivors. A preliminary report of HD IL-2 in a somewhat different schedule (five doses in a row, weekly for 4 weeks) in combination with the anti-PD-1 agent, pembrolizumab, in mRCC, demonstrated activity and showed that toxicity was manageable. ${ }^{23}$ Additional studies of anti-PD-1 agents with HD IL-2 are listed in online supplemental table S2. Combinations with other immunotherapies or targeted therapies should be investigated.

\section{CONCLUSIONS}

HD IL-2 therapy yields durable survival among a proportion of responding patients with $\mathrm{mM}$ and mRCC. Upfront identification of those likely to achieve this outcome remains elusive, however. In this report, long-term survival without subsequent systemic therapy was predominantly seen among those achieving CR. Although durable CRs have been previously reported, ${ }^{3-8} 1016-19$ this report demonstrates the potential for such responders to enjoy decadeslong survival without need for subsequent systemic therapy. Preliminary reports suggest that combining HD IL-2 with other active IT is associated with increased response rates and manageable toxicity. ${ }^{20} 23$ The current report supports the concept that clinical studies of HD IL-2 should continue to be evaluated in combination with CPIs, and other therapeutic agents in $\mathrm{mM}$ and $\mathrm{mRCC}$ to hopefully enhance response rate and yield a greater proportion of patients with durable survival.

\footnotetext{
Author affiliations

${ }^{1}$ Medicine, Loyola University Chicago Stritch School of Medicine, Maywood, Illinois, USA

${ }^{2}$ Earle A. Chiles Research Institute, Providence Medical Center, Portland, Oregon, USA

${ }^{3}$ Medicine, Vanderbilt University Medical Center, Nashville, Tennessee, USA

${ }^{4}$ Medicine, Massachusetts General Hospital, Boston, Massachusetts, USA

${ }^{5}$ Medicine, Levine Cancer Institute, Charlotte, North Carolina, USA

${ }^{6}$ Medicine, University of Michigan Health System, Ann Arbor, Michigan, USA

${ }^{7}$ Medicine, Indiana University Melvin and Bren Simon Cancer Center, Indianapolis, Indiana, USA

${ }^{8}$ Medicine, Nebraska Cancer Specialists, Omaha, Nebraska, USA

${ }^{9}$ Medicine, Hematology/Oncology Clinic, Baton Rouge, Louisiana, USA

${ }^{10}$ Medicine, University of Michigan Medical School, Ann Arbor, Michigan, USA

${ }^{11}$ Medicine, New York Medical College, Valhalla, New York, USA
}

Acknowledgements The authors would like to thank Prometheus Laboratories and Clinigen Group for production of the poster presentation at the Society for Immunotherapy of Cancer Annual Meeting, 2017.

Contributors JIC, BC, EJD, HK, AAm, AAl, TFL, RH, GPM, UV, DBJ, RLW, PHW, JPD contributed patient information for compilation of these data. JPD, PHW compiled the initial data report and presentation. JPD prepared the manuscript. All authors contributed to critical review of the manuscript.

Funding The authors have not declared a specific grant for this research from any funding agency in the public, commercial or not-for-profit sectors.

Competing interests JIC: speakers bureau: Bristol Myers Squibb (BMS), Merck; unpaid consultant, Clinigen Group; BC: research support: Clinigen, AstraZeneca, Galectin Therapeutics, consulting DMC: Merck, honoraria: BMS, Prometheus, travel: BMS, Agonox; EJD: research support: BMS, Incyte, Karyopharm, Genentech; HK: employee of Immuneering, consulting Replimune, SapVax; AAm: speakers bureau: BMS, Merck, Regeneron, Bioarray, research support: BMS, Merck, Exelixis, consultant: Novartis; AAI: consultant: AstraZeneca, Merck, Pfizer, BMS, travel expenses: Merck, BMS, research support: Genetech, BMS, Merck, Prometheus, Mirati, AstraZeneca, Roche, Bayer, Progenics, Astellas, Arcus, Harpoon Celgene, Janssen; TFL: research support: Abraxis, Acceleron, Amgen, Argos, AstraZeneca, Aveo, Biovex, BMS, Eisai, Lilly, GlaxoSmithKline, Roche, Immatics, Merck, Novartis, Pfizer, Prometheus, Synta, Threshold, Millenium, Tracon, Cerulean, EMD Serono, Macrogenics, Peloton, lovance, Medimmune, Dynavax, consultingPrometheus; RH: no disclosures; GPM: no disclosures; UV: consulting: BMS, Merck, Exelixis, Bayer, research support: BMS, Exelixis; DBJ: consulting: Array, BMs, Janssen, Merck, Novartis, research support: BMS, Incyte; RLW: no disclosures; PHW: no disclosures; JPD: consulting: Clinigen, Prometheus, DMCs: Merck, BMS, Eisai, Nektar, lovance, Amgen.

Patient consent for publication Not required.

Ethics approval The Institutional Review Boards of the institutions participating in this report approved the long-term databases used in this study, and all patients provided informed consent for collection of clinical data.

Provenance and peer review Not commissioned; externally peer reviewed.

Supplemental material This content has been supplied by the author(s). It has not been vetted by BMJ Publishing Group Limited (BMJ) and may not have been peer-reviewed. Any opinions or recommendations discussed are solely those of the author(s) and are not endorsed by BMJ. BMJ disclaims all liability and responsibility arising from any reliance placed on the content. Where the content includes any translated material, BMJ does not warrant the accuracy and reliability of the translations (including but not limited to local regulations, clinical guidelines, terminology, drug names and drug dosages), and is not responsible for any error and/or omissions arising from translation and adaptation or otherwise.

Open access This is an open access article distributed in accordance with the Creative Commons Attribution Non Commercial (CC BY-NC 4.0) license, which permits others to distribute, remix, adapt, build upon this work noncommercially, and license their derivative works on different terms, provided the original work is properly cited, an indication of whether changes were made, and the use is non-commercial. See: http://creativecommons.org/ licenses/by-nc/4.0/.

\section{ORCID iDs}

Peter H Wiernik http://orcid.org/0000-0003-1473-813X

Janice P Dutcher http://orcid.org/0000-0002-2267-9187

\section{REFERENCES}

1 Fyfe G, Fisher RI, Rosenberg SA, et al. Results of treatment of 255 patients with metastatic renal cell carcinoma who received high-dose recombinant interleukin-2 therapy. J Clin Oncol 1995;13:688-96.

2 Atkins MB, Lotze MT, Dutcher JP, et al. High dose recombinant interleukin 2 therapy for patients with metastatic melanoma: analysis of 270 patients treated between 1985 and 1993. J Clin Oncol 1999;17:2105-16.

3 Fisher RI, Rosenberg SA, Fyfe G. Long-term survival update for high-dose recombinant interleukin-2 in patients with renal cell carcinoma. Cancer J Sci Am 2000;6 Suppl 1:S55-7.

4 Clark JI, Wong MKK, Kaufman HL, et al. Impact of sequencing targeted therapies with high-dose interleukin-2 immunotherapy: an analysis of outcome and survival in patients with metastatic renal cell carcinoma from an ongoing observational IL-2 clinical trial: PROCLAIM ${ }^{\text {SM }}$. Clin Genitourin Cancer 2017;15:31-41

5 McDermott DF, Cheng S-C, Signoretti S, et al. The high-dose aldesleukin "select" trial: a trial to prospectively validate predictive models of response to treatment in patients with metastatic renal cell carcinoma. Clin Cancer Res 2015:21:561-8

6 Alva A, Daniels GA, Wong MKK, et al. Contemporary experience with highdose interleukin-2 therapy and impact on survival in patients with metastatic melanoma and metastatic renal cell carcinoma. Cancer Immunol Immunother 2016:65:1533-44.

7 Stenehjem DD, Toole M, Merriman J, et al. Extension of overall survival beyond objective responses in patients with metastatic renal cell carcinoma treated with high-dose interleukin-2. Cancer Immunol Immunother 2016:65:941-9

8 Clark JI, Curti B, Davis E. Long-Term disease-free survival of melanoma and renal cell cancer patients following high-dose interleukin-2. J Immunother Cancer 2017;5.

9 Dutcher JP, Schwartzentruber DJ, Kaufman HL, et al. High dose interleukin-2 (Aldesleukin) - expert consensus on best management practices-2014. J Immunother Cancer 2014;2:26.

10 Curti B, Daniels GA, McDermott DF, et al. Improved survival and tumor control with Interleukin-2 is associated with the development of immune-related 
adverse events: data from the PROCLAIM ${ }^{\mathrm{SM}}$ registry. J Immunother Cancer 2017;5:102.

11 Fishman M, Dutcher JP, Clark JI, Alva A, et al. Overall survival by clinical risk category for high dose interleukin-2 (HD IL-2) treated patients with metastatic renal cell cancer (mRCC): data from the PROCLAIMSM registry. J Immunother Cancer 2019;7.

12 Hodi FS, O'Day SJ, McDermott DF, et al. Improved survival with ipilimumab in patients with metastatic melanoma. N Eng/ J Med 2010;363:711-23.

13 McDermott DF, Drake CG, Sznol M, et al. Survival, durable response, and longterm safety in patients with previously treated advanced renal cell carcinoma receiving nivolumab. J Clin Oncol 2015;33:2013-20.

14 Motzer RJ, Tannir NM, McDermott DF, et al. Nivolumab plus ipilimumab versus sunitinib in advanced renal-cell carcinoma. $N$ Eng/ I Med 2018;378:1277-90.

15 Lebbé C, Meyer N, Mortier L, et al. Evaluation of two dosing regimens for nivolumab in combination with ipilimumab in patients with advanced melanoma: results from the phase IIIb/IV CheckMate 511 trial. J Clin Oncol 2019;37:867-75.

16 Klapper JA, Downey SG, Smith FO, et al. High-dose interleukin-2 for the treatment of metastatic renal cell carcinoma. Cancer 2008;113:293-301.

17 Payne R, Glenn L, Hoen H, et al. Durable responses and reversible toxicity of high-dose interleukin-2 treatment of melanoma and renal cancer in a community hospital biotherapy program. J Immunother Cancer 2014;2:13.
18 Chow S, Galvis V, Pillai M, et al. High-dose interleukin-2 - a 10-year single-site experience in the treatment of metastatic renal cell carcinoma: careful selection of patients gives an excellent outcome. J Immunother Cancer 2016;4:67.

19 Davar D, Ding F, Saul M, et al. High-dose interleukin-2 (HD IL-2) for advanced melanoma: a single center experience from the University of Pittsburgh cancer Institute. I Immunother Cancer 2017;5:74.

20 Prieto PA, Yang JC, Sherry RM, et al. CTLA-4 blockade with ipilimumab: longterm follow-up of 177 patients with metastatic melanoma. Clin Cancer Res 2012;18:2039-47.

21 Maker AV, Phan GQ, Attia P, et al. Tumor regression and autoimmunity in patients treated with cytotoxic $\mathrm{T}$ lymphocyte-associated antigen 4 blockade and interleukin 2: a phase I/II study. Ann Surg Oncol 2005; 12:1005-16.

22 Buchbinder El, Dutcher JP, Daniels GA, et al. Therapy with high-dose interleukin-2 (HD IL-2) in metastatic melanoma and renal cell carcinoma following PD1 or PDL1 inhibition. J Immunother Cancer 2019;7:49.

23 Chatzkel JA, Swank J, Ludlow S, et al. Overall responses with coordinated pembrolizumab and high dose IL-2 (5-in-a-row schedule) for therapy of metastatic clear cell renal cancer: a single center, single arm trial. JCO 2019;37:657. 